\title{
Knowledge, access and use of internet-based health information for personal healthcare among employees of the foremost Nigerian University
}

\author{
Benson Macaulay Oweghoro ${ }^{1}$, Ibrahim Taiwo Adeleke ${ }^{2,3,4}$, Patricia Philip Mshelia ${ }^{5}$, \\ Lateef Mosebolatan Ogundiran ${ }^{2,4}$, Aivonya Momoh Jimoh Yusuf ${ }^{2,4}$, Deborah Ifeoluwa Adeoti ${ }^{2,4}$ \\ ${ }^{1}$ Department of Library, Archive and Information Studies, University of Ibadan, Ibadan, Nigeria \\ ${ }^{2}$ Department of Health Information, Federal Medical Centre, Bida, Nigeria \\ ${ }^{3}$ Centre for Health \& Allied Researches, Bida, Nigeria \\ ${ }^{4}$ Health Informatics Research Initiatives in Nigeria, Bida, Nigeria \\ ${ }^{5}$ Department of Health Information Management, School of Health Technology, Maiduguri, Nigeria
}

\section{Email address:}

bmoweghoro@gmail.com (B. M. Oweghoro), ibratadeleke_aliseyin@yahoo.com (I. T. Adeleke), patriciamshelia@gmail.com (P. P. Mshelia), mosebolatan4real09@yahoo.com (L. M. Ogundiran), aivonya38@yahoo.com (A. M. J. Yusuf), adeoti_ifeoluwa@yahoo.com (D. I. Adeoti)

\section{To cite this article:}

Benson Macaulay Oweghoro, Ibrahim Taiwo Adeleke, Patricia Philip Mshelia, Lateef Mosebolatan Ogundiran, Aivonya Momoh Jimoh Yusuf, Deborah Ifeoluwa Adeoti. Knowledge, Access and Use of Internet-Based Health Information for Personal Healthcare among Employees of the Foremost Nigerian University. American Journal of Health Research. Special Issue: Health Information Technology in Developing Nations: Challenges and Prospects Health Information Technology. Vol. 3, No. 1-1, 2015, pp. 25-31.

doi: 10.11648/j.ajhr.s.2015030101.14

\begin{abstract}
Background: Accessibility and use of the internet-based health information are vital concepts in healthcare delivery. The Internet is changing not only the way patients get health information, but the way they interact with their healthcare providers and others alike. Several studies have explored the use of the Internet by the healthcare providers. However little is known about the extent to which individual patients use the Internet for their own personal healthcare information needs. Objective: This present study determined basic IT knowledge, skills and access to internet-based health information to address personal healthcare needs of the University of Ibadan employees. Methods: This is a cross-sectional study that deployed multi-stage sampling techniques. Result: Four hundred and two (82.0\%) of the 488 questionnaires distributed were analyzed. There were more (292, 72.6\%) non-teaching participants in the study. All (402, 100\%) participants were conversant with internet-based health information which was reported to have met their basic health needs. They all (402, $100 \%$ ) admitted that internet-based health information could be easily understood, and they mostly sought for it to equip themselves with prior knowledge on their ailments. However, the majority $(398,97.0 \%)$ searched for internet-based health information because they reported to have lost confidence in their healthcare providers. Conclusion: It is obvious from this study that most employees of University of Ibadan appreciated the importance of internet-based health information for personal healthcare and seek it for diverse personal reasons. The outcome of this study has the potentials to prepare healthcare professionals for dealing appropriately with internet-informed patients and restore their confidence. The Nigerian healthcare systems need to formulate policies on access and use of internet-based health information by their patients.
\end{abstract}

Keywords: Academics, Access, Knowledge, Health Information, Internet-Based Health Information, Personal Healthcare, Use

\section{Introduction}

The advent and global spread of the internet has brought with it the potentials to achieve universal access to healthcare information. The emerging technology has been described [1-
2] as having the capacities to enhance the current healthcare systems and improve quality of healthcare to the public. Good health is one of the basic necessities of individuals in any society, as it has strong influence on one's happiness, earning capacity, productivity, educational performance and longevity of life. Health is directly affected by people's 
personal circumstances, social conditions, physical environment and the home neighbourhood [3]. It is not a gainsaying the fact that the healthcare industry is information intensive. This has drastically been influenced by the concept of health informatics laying more emphasis on the use of computer-based application in the delivery and documentation of healthcare services [4-5]. Advance in computing and communication technologies has brought about telehealth with a greater impact on the delivery of healthcare [6]. Technology has played an important role in altering the traditional notions of the sick, thereby giving room for physician-patient interaction and health information has become conveniently available to many healthcare consumers [4-5].

Chronic diseases are some of the most challenging health problems in the world, and their burden on society is increasing. Successful management of most chronic health conditions involves self-care on an outpatient basis. This requires an integration of a variety of information and support resources available to consumers, and not completely relying on healthcare professionals [5]. In today's healthcare, it is obvious that more patients are likely to use the Internet as a source of health information [7]. When patients turn to the Internet for health information, it empowers them with relevant information capable of making them active participants in their healthcare. An instance [8] of a patient who was reported to be glued to his computer and the Internet to find answers to his mind-bordering queries as regards his sudden diagnosis of kidney cancer is no longer news. It could also be noted that there is no effective decision made and implemented to solve any health problem, until the full information relating to that problem and its surrounding is made available to the management. The importance of health literacy has been emphasized [9] to have the ability to obtain, read, understand and use health information for appropriate health decisions. Lack or little of health literacy may reduce the quality of treatment and increases the risk of medical error [10]. Mead et al [11] observed that people who believe that access to information will enable them to deal better with their health, will make concerted efforts to acquire relevant health information. As such; the study [11] established that the extent to which people are motivated to understand their health problems is important to their health.

Studies [12] have established that healthcare consumers do review medical treatment, procedures, healthcare products, hospitals and providers online. Murray et al [13] earlier reported that $85 \%$ of physicians surveyed in one national U.S survey had experienced patients bringing internet information to a visit. Fox [14] reported that as at 2012, 59\% of adult looked for health information online as the Internet becomes source of health information among individuals. Taylor and Leiman [15] divided users of internet-based health information into three. First are the accepting type who entirely depend on health professionals and second, the control type who depend solely on internet-based health information. The third are the informed type whose principal source of health information is the clinician but, they tend to view internet health information as an alternative medical source. Perceived health status has been viewed [16] as a personal perception and it represents the way an individual feels about his health. Houston \& Allison [17] reasoned that people with low perceived health status are more likely to utilize internet-based health information than those with higher status, and those with higher status search less than individuals with lower health status [18].

\subsection{Aims of the Study}

Several studies have explored the use of internet to obtain clinical information for patient care among medical practitioners in various health institutions across the globe. However little is known about the extent to which the patients themselves use the Internet for their own personal healthcare information needs. Understanding the extent to which the Internet is being used by individuals for health purposes and the effects it has on their healthcare needs and delivery would be necessary. This will help relevant authorities to identify the extent to which internet benefits are being realised and provide a context for fruitful discussions of the current and future roles of the Internet in healthcare delivery in Nigeria. Therefore, this present study determined IT knowledge, skills, access to, and the use of internet-based health information to serve individual's personal healthcare needs among employees of University of Ibadan, Nigeria.

\section{Methods}

\subsection{Background to the Study Area}

The study was limited to five selected faculties of the University of Ibadan which include Education, Science, Arts, Social Science and Medicine.

\subsection{Study Population}

The population of the study was made up of both academic and non-academic employees of the University of Ibadan, Ibadan. There are 1, 416 academic staff ranging from Assistant Lecturers to Professors, and 3, 470 non-academic staff.

\subsection{Study Design}

This is a descriptive study deployed to determine the use of internet-based health information.

\subsection{Sampling Techniques}

The study utilized multi-stage sampling technique in the recruitment of participants. Faculties were enrolled in the first stage, followed by subdivision of faculties into departments and some of the departments were selected, making the second stage. At the departmental level the employees were stratified into academic and non-academic staff. Using proportional allocation, selection was done at random and ten percent each was selected from both the academic staff (141) and non-academic (347). 


\subsection{Sampling Size}

A sample size of 488 participants was recruited into the study.

\subsection{Data Collection Tools}

The research instrument was developed by the authors and pretested through a pilot survey of some academic and nonacademic employees of the University. A Cronbach's alpha coefficient of 0.78 reliability was achieved. Copies of the questionnaire were distributed to the participants by the researcher personally. This is to ensure that the dichotomization in applying the instrument is maintained between the two groups.

\subsection{Data Analysis and Management}

The data collected were analyzed with the aid of SPSS Version 16 where simple frequency and percentage were computed.

\section{Results}

\subsection{Demographic Patterns of Participants}

Four hundred and two $(82.0 \%)$ of the 488 questionnaires distributed were analyzed. More than half $(207,51.5 \%)$ of the participants were males. Of all participants, the majority $(292,72.6 \%)$ were non-academic staff and most $(280,69.7 \%)$ were between 25 and 44 years of age with a significant few $(36,9.0 \%)$ below age 25 years. Majority $(208,51.7 \%)$ of the participants had put in between 11 and 20 service years at the university and $5.5 \%$ have had more than 30 years.

\subsection{ICT Literacy Level among Participants}

Table 1. Participants' ICT skills

\begin{tabular}{|c|c|c|c|}
\hline & Good (\%) & $\begin{array}{l}\text { Average } \\
(\%)\end{array}$ & $\begin{array}{l}\text { Poor } \\
(\%)\end{array}$ \\
\hline \multicolumn{4}{|l|}{ IT literacy level } \\
\hline $\begin{array}{l}\text { I can locate and run an application } \\
\text { program such as Microsoft Word }\end{array}$ & $402(100)$ & $0(0)$ & $0(0)$ \\
\hline $\begin{array}{l}\text { I can organize electronic files into } \\
\text { folders }\end{array}$ & $402(100)$ & $0(0)$ & $0(0)$ \\
\hline I can move files into folders & $393(97.8)$ & $9(2.2)$ & $0(0)$ \\
\hline I can use spread sheet package & $198(49.2)$ & $173(43.0)$ & $31(7.7)$ \\
\hline I can create basic presentation package & $402(100)$ & $0(0)$ & $0(0)$ \\
\hline $\begin{array}{l}\text { I can enter and update data in database } \\
\text { package such as Microsoft Access }\end{array}$ & $306(76.1)$ & $87(21.7)$ & $9(2.2)$ \\
\hline $\begin{array}{l}\text { I can use printers, scanners and other } \\
\text { computer peripherals }\end{array}$ & $396(98.5)$ & $6(1.5)$ & $0(0)$ \\
\hline \multicolumn{4}{|l|}{ Internet skills } \\
\hline I can download files from the Internet & $402(100)$ & $0(0)$ & $0(0)$ \\
\hline I can send and receive email messages & $402(100)$ & $0(0)$ & $0(0)$ \\
\hline $\begin{array}{l}\text { I can save document in various file } \\
\text { formats including HTML }\end{array}$ & $52(12.9)$ & $338(84.1)$ & $12(2.9)$ \\
\hline $\begin{array}{l}\text { I can communicate online with other } \\
\text { colleagues }\end{array}$ & 402 (100) & $0(0)$ & $0(0)$ \\
\hline $\begin{array}{l}\text { I can use web search engines to search } \\
\text { and retrieve health tips }\end{array}$ & $402(100)$ & $0(0)$ & $0(0)$ \\
\hline
\end{tabular}

The ICT literacy of participants was accessed at three levels. These include basic computer operations, proficiency in the use of application software and lastly, literacy of internet resources. As shown on Table 1 virtually all participants possess good basic knowledge of computer operations and the required conversance with the Internet. For instance, all $(402,100 \%)$ of the participants can organize electronic files into folders, create basic presentation package, download files from the Internet, send and receive email messages and use search engines to obtain health tips.

\subsection{Sources of ICT Literacy Acquisition among Participants}

Figure 1 below shows that commercial training shops top $(137,34.1 \%)$ the list of sources where participants obtained their skills in IT and the Internet.

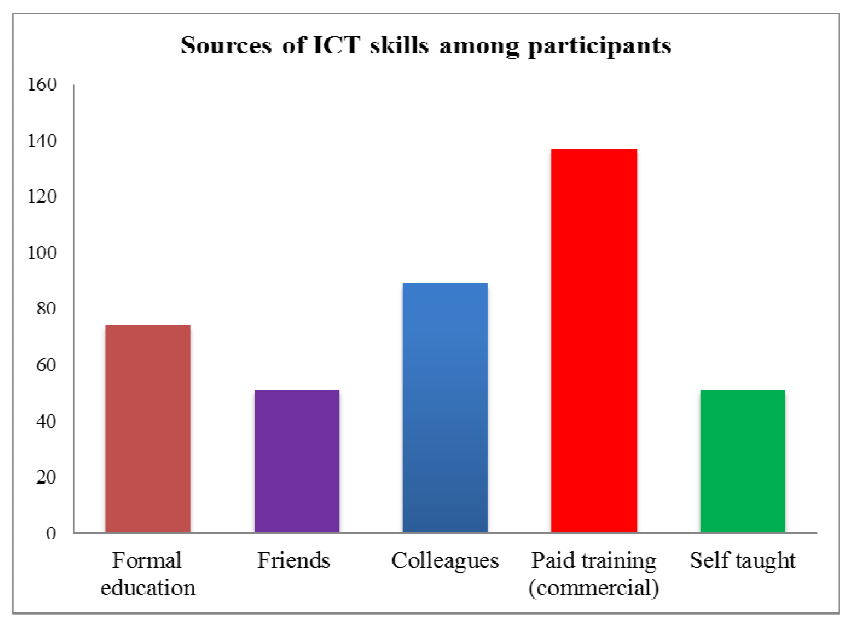

Fig 1. Sources ICT skills acquisition

\subsection{Awareness of Internet-Based Health Information for Personal Healthcare among Participants}

Table 2. Awareness on internet-based health information for personal healthcare needs

\begin{tabular}{lcl}
\hline & $\begin{array}{l}\text { Agreed } \\
(\%)\end{array}$ & $\begin{array}{l}\text { Disagreed } \\
(\%)\end{array}$ \\
\hline $\begin{array}{l}\text { Internet-based health information can be } \\
\text { beneficial to personal health needs }\end{array}$ & $402(100)$ & $0(0)$ \\
$\begin{array}{l}\text { The Internet-based health information is an } \\
\text { important compliment to providers' healthcare } \\
\text { service delivery. }\end{array}$ & $402(100)$ & $0(0)$ \\
$\begin{array}{l}\text { The internet-based health information is not } \\
\text { meant for personal use }\end{array}$ & $17(4.2)$ & $385(95.8)$ \\
$\begin{array}{l}\text { I know the appropriate website to source for my } \\
\text { health information needs online }\end{array}$ & $402(100)$ & $0(0)$ \\
$\begin{array}{l}\text { I can source for the required health information } \\
\text { online }\end{array}$ & $402(100)$ & $0(0)$ \\
$\begin{array}{l}\text { Internet-based health information can be accessed } \\
\text { freely online }\end{array}$ & $386(96.0)$ & $16(4.0)$ \\
$\begin{array}{l}\text { Internet-based health information is easily } \\
\text { understood }\end{array}$ & $402(100)$ & $0(0)$ \\
$\begin{array}{l}\text { Internet-based health information can be accessed } \\
\text { while at home }\end{array}$ & $402(100)$ & $0(0)$ \\
\hline
\end{tabular}

As shown on Table 2, there was high level of awareness of internet-based health information among the participants. 
They all (402, 100\%) admitted that internet-based health information can be useful to their individual health and that internet-based health information is an important compliment to providers' healthcare efforts. However, they mostly (385, 95.8) disagreed with the statement that online health information is not meant for personal use.

\subsection{Predictors of Internet-Based Health Information Seeking Behaviour}

The decision to seek internet-based health information is influenced by various factors as it affects individuals. Table 3 identifies factors that determine participants' quest for internet-based health information. All the participants in the two segments, academics $(110,100 \%)$ and non-academics $(292,100 \%)$ agreed that distance to health facilities, quest for prior knowledge about personal health needs, cheaper cost and concerns over confidentiality were the major factors necessitating their search for online health information. It is worthy of mention that the majority (academics 104, 94.6\%; non-academics $286,97.9 \%$ ) used the internet-based health information mostly because they had lost confidence in the healthcare providers.

Table 3. Predictors of internet-based health information seeking behaviour

\begin{tabular}{|c|c|c|c|c|}
\hline & \multicolumn{2}{|c|}{ Academic $(n=110)$} & \multicolumn{2}{|c|}{ Non-academic $(n=292)$} \\
\hline & Agreed (\%) & Disagreed (\%) & Agreed (\%) & Disagreed (\%) \\
\hline $\begin{array}{l}\text { Due to the distance to health centre, I always prefer to } \\
\text { source for health information on the Internet }\end{array}$ & $110(100)$ & $0(0)$ & $292(100)$ & $0(0)$ \\
\hline $\begin{array}{l}\text { I source for internet-based health information in order to } \\
\text { gain a fore knowledge of my health needs }\end{array}$ & $110(100)$ & $0(0)$ & $292(100)$ & $0(0)$ \\
\hline $\begin{array}{l}\text { I seek internet-based health information because it is } \\
\text { cheaper }\end{array}$ & $110(100)$ & $0(0)$ & $292(100)$ & $0(0)$ \\
\hline $\begin{array}{l}\text { I seek internet-based health information because I don't } \\
\text { feel free to discuss my health needs with colleagues }\end{array}$ & $110(100)$ & $0(0)$ & $292(100)$ & $0(0)$ \\
\hline $\begin{array}{l}\text { I seek internet-based health information because friends } \\
\text { recommended it }\end{array}$ & $9(8.2)$ & $101(91.8)$ & $20(6.8)$ & $272(93.2)$ \\
\hline $\begin{array}{l}\text { I seek internet-based health information because I had lost } \\
\text { confidence in the healthcare providers }\end{array}$ & $104(94.5)$ & $6(5.5 \%)$ & $286(97.9)$ & $6(2.1)$ \\
\hline $\begin{array}{l}\text { I seek internet-based health information because I was not } \\
\text { given due attention at the hospital }\end{array}$ & $2(1.8)$ & $108(98.2)$ & $6(2.1)$ & $286(97.9)$ \\
\hline $\begin{array}{l}\text { I seek internet-based health information because I was } \\
\text { dissatisfied with services rendered in the hospital }\end{array}$ & $3(2.7)$ & $107(97.3)$ & $20(6.8)$ & $272(93.2)$ \\
\hline $\begin{array}{l}\text { I seek internet-based health information because I want to } \\
\text { authenticate care rendered by healthcare providers }\end{array}$ & $3(2.7)$ & $107(97.3)$ & $28(9.6)$ & $264(90.4)$ \\
\hline $\begin{array}{l}\text { I seek internet-based health information because I want to } \\
\text { personally participate in care of my health }\end{array}$ & $0(0)$ & $110(100)$ & $(4.2)$ & $280(95.8)$ \\
\hline
\end{tabular}

Table 4. Uses of internet-based health information

\begin{tabular}{|c|c|c|c|c|}
\hline & \multicolumn{2}{|c|}{ Academic $(n=110)$} & \multicolumn{2}{|c|}{ Non-academic $(\mathrm{n}=\mathbf{2 9 2})$} \\
\hline & Agreed (\%) & Disagreed (\%) & Agreed (\%) & Disagreed (\%) \\
\hline I use internet-based health information to treat minor ailments & $110(100)$ & $0(0)$ & $292(100)$ & $0(0)$ \\
\hline $\begin{array}{l}\text { I depend on internet-based health information for the care of } \\
\text { myself and family }\end{array}$ & $110(100)$ & $0(0)$ & $292(100)$ & $0(0)$ \\
\hline $\begin{array}{l}\text { I use internet-based health information to find out about my } \\
\text { health needs when I am in doubt }\end{array}$ & $110(100)$ & $0(0)$ & $292(100)$ & $0(0)$ \\
\hline $\begin{array}{l}\text { I use internet-based health information to confirm what my } \\
\text { healthcare provider tells me }\end{array}$ & $110(100)$ & $0(0)$ & $292(100)$ & $0(0)$ \\
\hline I consult internet-based health information on a daily basis & $3(2.7)$ & $107(97.3)$ & $9(3.1)$ & $283(96.9)$ \\
\hline $\begin{array}{l}\text { I prefer to get health information from the Internet than } \\
\text { consulting medical personnel }\end{array}$ & $110(100)$ & $0(0)$ & $292(100)$ & $0(0)$ \\
\hline $\begin{array}{l}\text { Internet-based health information provide me with all I need to } \\
\text { know about my health }\end{array}$ & $0(0)$ & $110(100)$ & 292 (100) & $0(0)$ \\
\hline
\end{tabular}

\subsection{Uses of Internet-Based Health Information}

Table 4 reveals utilization assessment of internet-based health information among participants. All the participants $(402,100 \%)$ use internet-based health information to treat minor ailments of self and their family members. All of them admitted that internet-based health information do provide all they need to know about their health. However, the vast majority $(390,97.0 \%)$ indicated that they did not use the Internet daily.

\section{Discussion}

Good quality health information is essential for greater patients' involvement in their healthcare and greater attention is required to improve access to patient health information, to be used by patients and healthcare providers for informed decision making [19]. In the same vein, consumer effective participation in personal healthcare is an essential ingredient that impact healthcare outcomes and costs. Partnerships 
between healthcare providers and consumers have been advocated [20] as harbinger of best practices and improved health outcomes. When patients are well informed through the impressive tools of computer and the Internet, their communication skills improve and they take decisive actions to improve their health, monitor their health status and even challenge professionals to improve their healthcare delivery [20]. Our study of knowledge, skills, access and use of internet-based health information among University of Ibadan employees suggests that getting prior knowledge on personal health puzzles helps healthcare consumers prepare for the challenges ahead and participate in their healthcare processes. The findings reveal that both academic and nonacademic employees of the University use internet-based health information to know something about their health status and that of their families, treat minor sickness, and that internet-based health information provides all they need to know about their health. This is in line with a study from North Carolina USA, [21] where participants searched the Internet for information about treatment, coping with side effects, and treatment options.

Clinicians and researchers pay particular attention to technology as a promising tool to empower patients through personal healthcare management skills and to improve healthcare communication with providers. Current trends indicate that more and more patients are likely to use the Internet as a source of health information [7]. In line with this, participants in this study possess good knowledge of computer operations which they mostly obtained from commercial training shops. In the same way, they were conversant with the Internet so much that they appreciated its ability to offer useful health information which was admitted to be useful to their individual healthcare decisions. Possession of good ICT knowledge among participants is a fundamental factor in their ability to access and use internetbased health information. This corroborates earlier reports [22-23] that good knowledge of technology significantly influences users' acceptance. In effects, user acceptance influences access and use. This study like that of Gustafson et al [24], discovers that obtaining health information from the Internet gave participants the required confidence to inquire and relate well with their healthcare providers. A study [25] has suggested computer and internet-based health information as a tool to improve patient's quality of life and promote more efficient use of healthcare. Although some studies [26-28] reported apprehensions about possible threat to doctor-patient relationship when computer and internet were used, other studies [29, 2, and 13] have favoured these technologies as effective tools for the improvement of doctorpatient or provider-consumer relationships. Moreover, involving the patients in their healthcare has been recognized as an important tool to improve health information and care quality [30, 25] and improve clinical outcomes [31].

From this study, the decision to seek internet-based health information is influenced by various factors such as distance to health facilities, quest for knowledge about personal health needs, cheaper cost and concerns over confidentiality. It is noteworthy that loss of confidence in healthcare providers was a major factor. Rost [32] has noticed that malpractices, fraud and love of money as against interests of patients have affected the reverence with which consumers used to hold physicians. In addition, reposing confidence and trust in providers [33] are more closely associated with patients' overall evaluations of their hospitals and healthcare providers. Invariably, perceived lack of information does contribute to loss of confidence [34]. The Internet was though searched due to loss of confidence in providers among other reasons; it is freely available to meet information seeking behaviour and demands of consumers. Unguided access and uncensored data may produce adverse effects. Therefore, healthcare providers in their diverse specialties should participate in feeding the Internet with the correct and up-to-date health information. Since healthcare professionals have the potentials to assist patients to make sense of health information from the Internet [7] and improve patientphysician relationship [28].

\subsection{Study Limitations}

There was a little delay in retrieving completed questionnaires during data collection. This practically prolonged the time taken on data collection and misplacement of many questionnaires.

\section{Conclusion}

Man is a curious being and will continue to search for knowledge on issues that borders on his health issues. It has been said that knowledge of technology significantly influences user's acceptance. Also, the ability to access and use a particular technology will be determined by the level of the person's literacy of the technology. This has been found to be true of academic and non-academic staff of the University of Ibadan in terms of their knowledge, access and use of internet-based health information for personal healthcare. The employees of the University possess good ICT knowledge and skills; they access and use internet-based health information for their health needs, decision making and are able to get possible help in the absence of care providers. We also concluded that both groups (academics and nonteaching) have similarity in knowledge, access and use of the internet-based health information for personal healthcare. The outcome of this study has the potentials to enable healthcare professionals deal appropriately with internet-informed patients and restore their confidence. The Nigerian healthcare system needs to formulate policies on access and use of interned-based health information by patients.

\section{Acknowledgement}

The authors wish to recognize Messrs. Moses Achinbee, Danjuma Aliyu and Ahmed B. Jimoh for their thoughtful comments on the final manuscript. All the four hundred and two employees of the University of Ibadan who participated in this study are hereby acknowledged. 


\section{References}

[1] I. T. Adeleke, M. A. Asiru, B. M. Oweghoro, A. B. Jimoh, A. M. Ndana. Computer and internet use among tertiary healthcare providers and trainees in a Nigerian public hospital. American Journal of Health Research. Special Issue: Health Information Technology in Developing Nations: Challenges and Prospects Health Information Technology. 2015;3(1-1):110. doi: 10.11648/j.ajhr.s.2015030101.11

[2] I. T. Adeleke, A. H. Lawal, R. A. Adio, A. A. Adebisi. Information technology skills and training needs of health information management professionals in Nigeria: a nationwide study. Health Information Management Journal, 2014. doi.org/10.12826/18333575.2014.0002.Adeleke.

[3] P. L. Knox. Medical deprivation, area deprivation and public policy. Social Science and Medicine. 2009; 13:111-121.

[4] P. Whitten, M. Notman, C. Maynard, R. Henry, R. Glandon. Interactive health communication technologies in the public health sector: positive perceptions still outpace actual utilization. J Technol HumServ 2004; 22: 25-40.

[5] J. G. Anderson. Consumers of ehealth: patterns of use and barriers. Soc Sci Comp Rev. 2004;22:242-8.

[6] V. Thurmond. Telehealth in the Year 2010. Online Journal of Health Informatics. Available at: www.ojni.org/52/article3.htm Accessed on: December 4, 2014.

[7] G. Dolan, R. Iredale, R. Williams, J. Ameen. Consumer use of the internet for health information: a survey of primary care patients. International Journal of Consumer Studies. 2004; 28(2):147-153.

[8] J. Shapiro. Patients turn to the Internet for health information, 2007. Available at: www.npr.org/templates/story/story.php?storyId=15166387. Accessed on December 5, 2014.

[9] Anonymous. Roundtable on Health Literacy; Board on Population Health and Public Health Practice; Institute of Medicine (10 February 2012). Facilitating state health exchange communication through the use of health literate practices: workshop summary. National Academies Press, p1. ISBN978-0-309-22029-2.

[10] A. Pleasant, J. McKinney. Coming to consensus on health literacy measurement: an online discussion and consensusgauging process. Nursing Outlook. 2011;59(2):95-106. doi:10.1010/j.outlook.2010.12.006.

[11] N. Mead, R. Varnam, A. Rogers, M. Roland. What predicts patients' interest in the Internet as a health resource in primary care in England? Journal of Health Services Research and Policy. 2003;8(1):33-39.

[12] L. M. Verhoef, T. H. Van de Belt, L. J. Engelen, L. Schoonhoven, R. B. Kool. Socil media and rating sites as tools to understanding quality care: a scoping review. J Med Internet Res. 2014;16(2):e56. PMID: 24566844.

[13] E. Murray, L. Bernard, P. Lance, et al. The impact of health information on the Internet on the physician-patient relationship: patient perceptions. Arch Intern Med. 2003; 163: 1727-34. Available at: www.archinte.jamanetwork.com Accessed on December 6, 2014.
[14] S. Fox. The social life of health 2011. Available at: www.pewinterrel.org/files/oldmedia/files/Reports/2011/PIP_Social_life_of_Health_Info.pdf. Accessed on: November 5, 2014.

[15] H. Taylor, R. Leitman. The increasing impact of eHealth on consumer behavior. Health Care News. 2001;1(21):1-9.

[16] P. M. Fayers, M. A. Sprangers. Understanding self-rated health. Lancet. 2002;359, 187-8.

[17] K. T. Houston, J. J. Allison. Users of internet health information:Differences by health status. Journal of Medical Internet Research. 2002;4(2):e7.

[18] L. Baker, T. H. Wagner, S. Singer, M. K. Bundorf. Use of the Internet and email for healthcare information. JAMA. 2003;289:2400-06.

[19] A. Coulter, J. Ellins, D. Swain, et al. Assessing the quality of information to support people in making decisions about their health and healthcare. Picker Institute, Europe. Available at: www.pickereurope.org Accessed on: December 6, 2014.

[20] G. Seckin. Patients as information managers: the internet for successful self-healthcare and illness management. Open Longevity Science. 2010; 4: 36-42.

[21] B. K. Rimer, E. J. Lyons, K. M. Ribisl, et al. How new subscribers use cancer-related online mailing lists. J Med Internet Res 2005;7(3):e32. doi:10.2196/jmir.7.3.e32.

[22] J. Fulk, J. Schmitz, C. Steinfield. A social influence model of technology use. In: J. Fulk \& C. Steinfield, Organisations and Communication Technology, Newbury Park, Sage. 1990: pp.117-140.

[23] V. Venkatesh, F. D. Davis. A theoretical extension of the technology acceptance model: four longitudinal field studies. Management Science. 2000;46(2):186 -204.

[24] D. Gustafson, R. Hawkins, F. McTavish, et al. (2008): Internet-based interactive support for cancer patients: are integrated systems better? J Commun; 58: 238-57.

[25] D. H. Gustafson, R. Hawkins, E. Boberg, et al. Impact of a patient-centred, computer-based health information/support system. Am J Prev Med 1999;16(1):1-9.

[26] L. A. Huryk. Factors influencing nurses' attitudes towards healthcare information technology. Journal of Nursing Management. 2010;18(5): 606-612.

[27] Institute of Medicine. To err is human: building a safer health system. Institute of Medicine Report on Medical Errors. Washington, DC: National Academies Press, 2000.

[28] B. S. Gerber, A. R. Eiser. The patient-physician relationship in the Internet age: future prospects and the research agenda. J Med Internet Res 2001;3(2):e15. doi:10.2196/jmir.3.2.e15. PMID: 11720957 PMCID: PMC1761896.

[29] I. T. Adeleke, S. A. Erinle, A. M. Ndana, T. C. Anamah, O. A. Ogundele, D. Aliyu. Health information technology in Nigeria: stakeholders' perspectives of nationwide implementations and meaningful use of the emerging technology in the most populous black nation. American Journal of Health Research. Special Issue: Health Information Technology in Developing Nations: Challenges and Prospects Health Information Technology. 2015; 3(1-1): 17-24. doi: 10.11648/j.ajhr.s.2015030101.13. 
[30] M. Lauterslager, H. J. Brouwer, J. Mohrs, P. J. E. Bindels, H. G. L. M. Grundmeijer. The patient as a source to improve medical record. Family Practice. 2002;19(2):167-171.

[31] K. Luxford, S. Sutton. How does patient experience fit into the overall healthcare picture? Patient Experience Journal. 2014;1(1):20-27.

[32] P. Rost. People should not trust their doctors. Available at: www.hiffingtopost.com/dr-peter-rost/dont-trust-yourdoctor_b_18997.html. Accessed on December 8, 2014.
[33] S. Joffe, M. Manocchia, J. C. Weeks, P. D. Cleary. What do patients value in their hospital care? An empirical perspective on autonomy centred bioethics. J Med Ethics. 2003;29:103108. doi: 10.1136/jme.29.2.103.

[34] D. A. Gust, A. Kennedy, I. Shui, P. J. Smith, G. Nowak, L. K. Pickering. Parent attitudes toward immunizations and healthcare providers. Am J Prev Med. 2005;29(2):105-112. doi:10.1016/j.amepre.2005.04.010. 